Research Article

\title{
A comparative study of probiotic, prokinetic based triple therapy with USFDA regimen in the eradication of Helicobacter pylori in a tertiary care hospital
}

\author{
Bharath Kumar V. D. ${ }^{1 *}$, Jayanthi C. R. ${ }^{2}$, Sushma M. ${ }^{2}$
}

\begin{abstract}
${ }^{1}$ Department of pharmacology, BGS Global institute of medical sciences, Bangalore, Karnataka, India, ${ }^{2}$ Department of pharmacology, Bangalore medical college and research institute, Bangalore, Karnataka, India
\end{abstract}

Received: 6 December 2015

Accepted: 7 January 2016

\section{*Correspondence to: \\ Dr. Bharath Kumar.V.D, \\ Email: bmcplacebo@gmail.com}

Copyright: (C) the author(s), publisher and licensee Medip Academy. This is an open-access article distributed under the terms of the Creative Commons Attribution Non-Commercial License, which permits unrestricted noncommercial use, distribution, and reproduction in any medium, provided the original work is properly cited.

\begin{abstract}
Background: Helicobacter pylori infection has been associated with peptic ulcer disease, gastric carcinoma and gastric mucosa associated lymphoid tissue (MALT) lymphoma. Its eradication is important and current regimens are associated with antibiotic resistance, side effects and poor patient compliance. Probiotics supplementation can overcome the above problem and additions of prokinetics improve dyspepsia symptoms and thereby improve patient compliance. So the aim of the study was to compare efficacy and safety of standard United States Food and Drug Administration (USFDA) regimen with probiotic, prokinetic based novel regimen.
\end{abstract}

Methods: 100 patients diagnosed with $H$. pylori infection were randomly assigned into two eradication regimen groups viz., group A and group B. Group A received standard USFDA regimen, amoxicillin $1 \mathrm{gm}$, lansoprazole $30 \mathrm{mg}$ and clarithromycin $500 \mathrm{mg}$ twice a day for 2 weeks and group B received a probiotic and prokinetic itopride $50 \mathrm{mg}$ thrice daily, pantoprazole $40 \mathrm{mg}$, amoxicillin $1 \mathrm{gm}$ and clarithromycin $500 \mathrm{mg}$ twice daily for 2 weeks. Patients with Rapid Urease Test (RUT) and histopathology reports negative for $H$. pylori were considered as eradicated and then the percentage of eradication rate in both groups was compared.

Results: $H$. pylori eradication rates were more in group B compared to group A ( $84 \%$ vs $70 \%, p=0.096$ at $95 \% \mathrm{CI})$. The occurrence of side effects was less in group B compared to group A $(30 \%$ vs $46 \%$, p= 0.099). Diarrhoea was statistically less in group B compared to group A $(\mathrm{p}<0.05)$.

Conclusions: Probiotics supplementation increases eradication rates of anti $H$. pylori therapy and improves tolerability by reducing side effects especially diarrhoea. Prokinetics and probiotic based novel regimen improved dyspepsia symptoms and patient compliance.

Keywords: Helicobacter pylori, Probiotics, Prokinetics, Eradication rate, Safety, Compliance

\section{INTRODUCTION}

Helicobacter pylori is a gram negative, micro aerophilic, rod shaped, flagellate bacteria which resides in stomach of $\sim 50 \%$ of world's population. It plays a key role in the pathogenesis of acid-peptic diseases, gastric and duodenal ulcers, gastric adenocarcinoma, gastric MALT lymphoma. ${ }^{1}$
Worldwide, $>80 \%$ of duodenal ulcers and $>60 \%$ of gastric ulcers are related to $H$. pylori colonization. Because of its critical role in the pathogenesis of peptic ulcers, its eradication is vital in treating peptic ulcers. Eradication of $H$. pylori is also indicated in the treatment of mucosa-associated lymphoid tissue lymphomas of the stomach, which can regress significantly after such treatment. Treatment of $H$. pylori is of no benefit in the treatment of gastric adenocarcinoma, but prevention of $H$. pylori colonization could potentially prevent gastric 
malignancy and peptic ulceration. Effective treatment for H.pylori should achieve an eradication rate of over $90 \%$. It is important to select an ideal regimen for eradication. ${ }^{2}$

Single antibiotic regimens are ineffective in eradicating $H$. pylori infection and lead to microbial resistance. Combination therapy with two or three antibiotics with PPIs is associated with the highest rate of $H$. pylori eradication. Addition of proton pump inhibitor significantly enhances the effectiveness of $H$. pylori antibiotic regimens containing amoxicillin or clarithromycin. $^{2,3}$

The duration of triple therapy vary in the American College of Gastroenterology Guidelines (10-14 days) and in the Maastricht III Consensus Report guidelines (7 days). ${ }^{4}$ US-FDA has recommended a regimen consisting of lansoprazole, amoxicillin and clarithromycin for 14 days and with $>90 \%$ eradication rates. ${ }^{2}$ The same regimen used in South East Asian patients showed 87\% eradication rate. $^{5}$

Poor patient compliance is linked to the medicationrelated side effects experienced by as many as half of patients taking triple-agent regimens, and to the inconvenience of three or four drug regimens administered several times per day. Anti $H$. pylori kit that combines the daily doses into one convenient unit are available and may improve patient compliance. The emergence of resistance to clarithromycin and metronidazole increasingly is recognized as an important factor in the failure to eradicate $H$. pylori. In areas with a high frequency of resistance to clarithromycin and metronidazole, a 14-day, quadruple-drug regimen (three antibiotics combined with a proton pump inhibitor) generally is an effective therapy.

In order to overcome antibiotic resistance, eradication failure, high expenses, poor patient compliance and tolerability there is a constant search for newer drugs and regimens in eradicating $H$. pylori. Many studies have shown that probiotics are known to play a major role in eradication of $H$. pylori. Its administration improves antibiotic tolerability by reducing side effects like diarrhoea, bloating and taste disturbances. Probiotics also improves $H$. pylori gastritis and decrease $H$. pylori density in gastric mucosa. Long term intake of probiotics reduces the risk of development of disorders associated with high degrees of gastric inflammation. ${ }^{6}$

Prokinetics addition leads to improvement of dyspepsia symptoms, leading to better patient compliance and quality of life. ${ }^{7}$

Therefore, the present study was designed to compare the eradication rates and safety of standard USFDA regimen (lansoprazole, amoxicillin and clarithromycin) with a novel combination regimen with a probiotic, prokinetic (itopride), pantoprazole, amoxicillin and clarithromycin practiced in department of surgical gastroenterology,
Victoria hospital, Bangalore Medical College and Research Institute.

\section{METHODS}

\section{Source of data}

Outpatients and inpatients in the department of surgical gastroenterology, Victoria hospital, Bangalore.

\section{Methods of collection of data}

Study design: comparative, prospective study.

Sample design: random sampling.

Sample size: 100 patients with acid peptic disease

\section{Inclusion criteria}

Patients of either sex aged between 18-60 years. Patients with acid peptic disease (non-ulcer dyspepsia, gastroduodenal ulcers and erosions, GERD) with endoscopically proven H.pylori infection by rapid urease test and histopathological examination. Patient who gives written informed consent.

\section{Exclusion criteria}

Patients on NSAIDS, anticoagulants, antibiotics or corticosteroids in the past 30 days. Patients with co morbid conditions - ischaemic heart disease, congestive cardiac failure, liver disease and renal failure. Pregnant and lactating women.

Patients with features of portal hypertension, gastric or any other malignancy or evidence of significant gastrointestinal bleed. Patients with known allergy to medications used. Patients with previous gastric or oesophageal surgery. Non complying patients who are unable to give consent for the study.

\section{Methodology}

The present study was undertaken after approval from institutional ethics committee.

100 patients who were diagnosed with $H$. pylori infection by upper GI endoscopy, histopathological examination and rapid urease test were enrolled in the study after obtaining informed consent and they were randomly assigned into two different eradication treatment groups.

Group A received standard USFDA regimen with amoxicillin $1 \mathrm{gm}$, lansoprazole $30 \mathrm{mg}$ and clarithromycin $500 \mathrm{mg}$ twice a day for 2 weeks.

Group B received a probiotic and prokinetic itopride 50 $\mathrm{mg}$ thrice daily, pantoprazole $40 \mathrm{mg}$, amoxicillin $1 \mathrm{gm}$ and clarithromycin $500 \mathrm{mg}$ twice daily for 2 weeks. Probiotic used in this study was Probiza (brand name) containing Lactobacillus acidophilus 0.48 billion cells, Lactobacillus rhamnosus 0.48 billion cells, 
$\begin{array}{lllll}\text { Bifidobacterium } & \text { longum } & 0.48 & \text { billion } & \text { cells } \\ \text { Bifidobacterium } & \text { bifidum } & 0.48 & \text { billion } & \text { cells, }\end{array}$ Saccharomyces boulardii 0.1 billion cells, Streptococcus thermophilus 0.48 billion cells, Fructo-oligosaccharides $300 \mathrm{mg}$.

Patients were instructed to take itopride, pantoprazole and lansoprazole half an hour before food but other drugs to be taken 15-20 minutes after food. Pantoprazole and itopride were given to group B and lansoprazole to group A once daily in the morning for next 4 weeks.

Patients were followed up at the end of $2^{\text {nd }}$ and $6^{\text {th }}$ week. At $6^{\text {th }}$ week, rapid urease test and endoscopy were repeated, those patients with RUT and histopathology negative were considered responders and then the percentage of responders in both groups were compared. Demographic data, history of habits, drug intake, clinical examination and details of drug prescription by the treating gastroenterologist were recorded in the study proforma.

Parametric variables were analyzed using student $t$ test and $\mathrm{z}$ test. Non parametric variables were analyzed using Fischer exact test and Chi- square test.

\section{RESULTS}

The present prospective, randomized, comparative study done at Victoria hospital, Department of surgical gastroenterology, Bangalore medical college and Research Institute revealed the following results. Totally 100 patients diagnosed with $H$. pylori infections were evaluated for efficacy and safety. All the 100 patients completed the study and there were no drop outs. Group A (50) received USFDA regimen and group B (50) probiotic, prokinetic based triple regimen.

Table 1: Comparison of rapid urease test (RUT) for detection of $\mathrm{H}$.pylori in two groups of patients studied (Group A vs. group B).

\begin{tabular}{|lllll|}
\hline RUT & Day 1 & & Day 42-44 & $\left(6^{\text {th }}\right.$ week $)$ \\
& Group A & Group B & Group A & Group B \\
\hline Positive & 50 & 50 & 15 & 8 \\
\hline Negative & 0 & 0 & 35 & 42 \\
\hline
\end{tabular}

Table 2: Comparison of histopathological detection of $H$. pylori by Giemsa stain in two groups of patients studied (Group A vs. group B).

\begin{tabular}{|lllll|}
\hline $\begin{array}{l}\text { Giemsa } \\
\text { stain }\end{array}$ & Day 1 & & \multicolumn{2}{c|}{ Day 42-44 } \\
\hline & Group A & Group B & Group A & Group B \\
\hline Positive & 50 & 50 & 15 & 8 \\
\hline Negative & 0 & 0 & 35 & 42 \\
\hline
\end{tabular}

In the present study both the treatment groups matched with respect to age, gender, diet, habits, co-morbid conditions and area of distribution. In group A, 35 patients became negative for RUT (Table 1) and histopathological detection (Table 2) of $H$. pylori, whereas in group B 42 patients were negative at day 4244. Based on the above tests the eradication rates were more with the group $\mathrm{B}$ in comparison to the group $\mathrm{A}$ (84\% vs 70\%, $\mathrm{p}=0.096$ ) (Figure 1 ).

The following side effects were reported in Group A and Group B viz., nausea, vomiting, abdominal pain, diarrhoea and taste disturbances. Incidence of diarrhoea was statistically less in Group B compared to Group A $(p<0.05)$ (Table 3). There was no change in laboratory parameters in both the groups at day $42-44$ compared to day 1 (Figure 2-6).

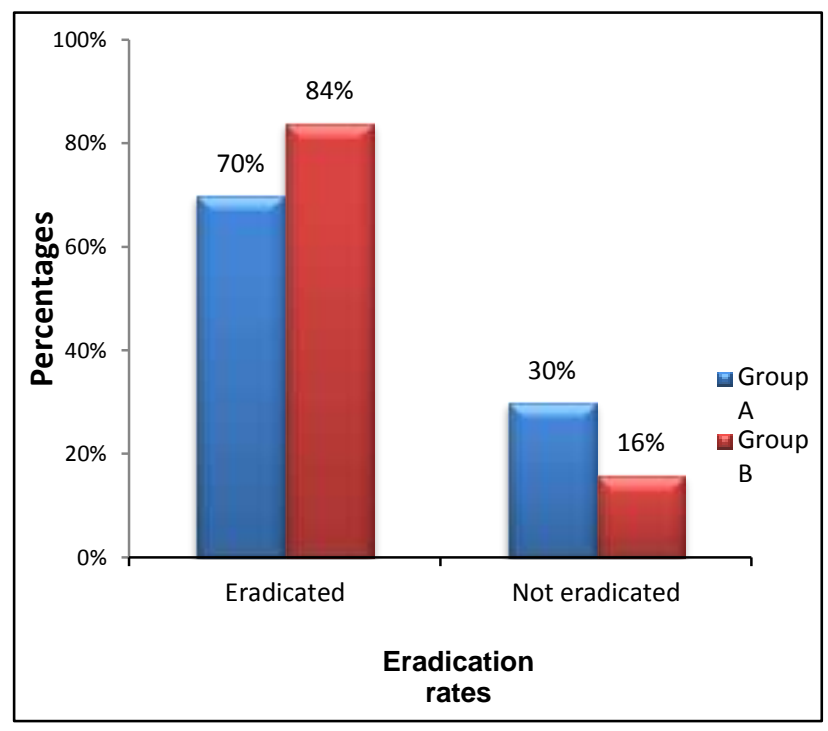

Figure 1: Eradication rates between two groups.

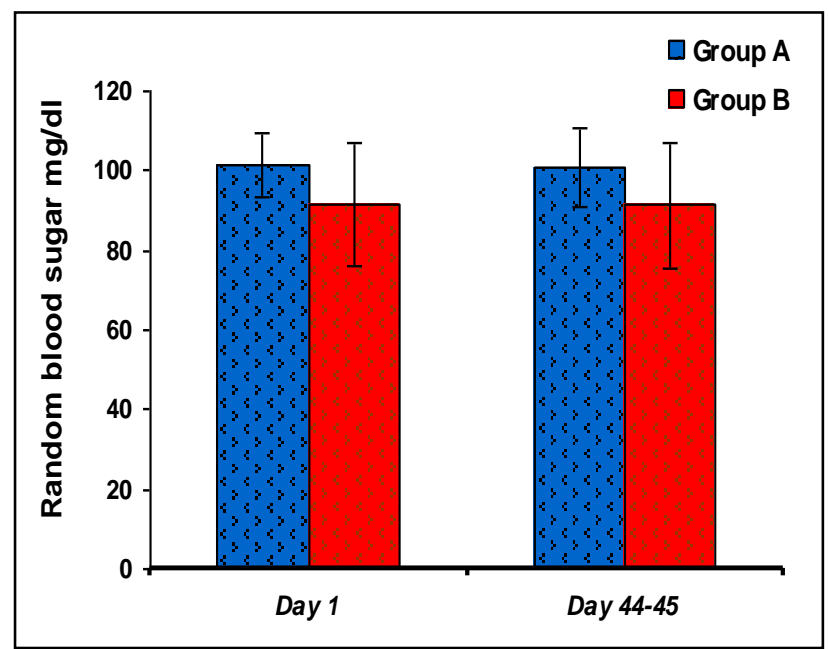

Figure 2: Random blood sugar in two groups of patients studied on day 1 and day 42-44. 


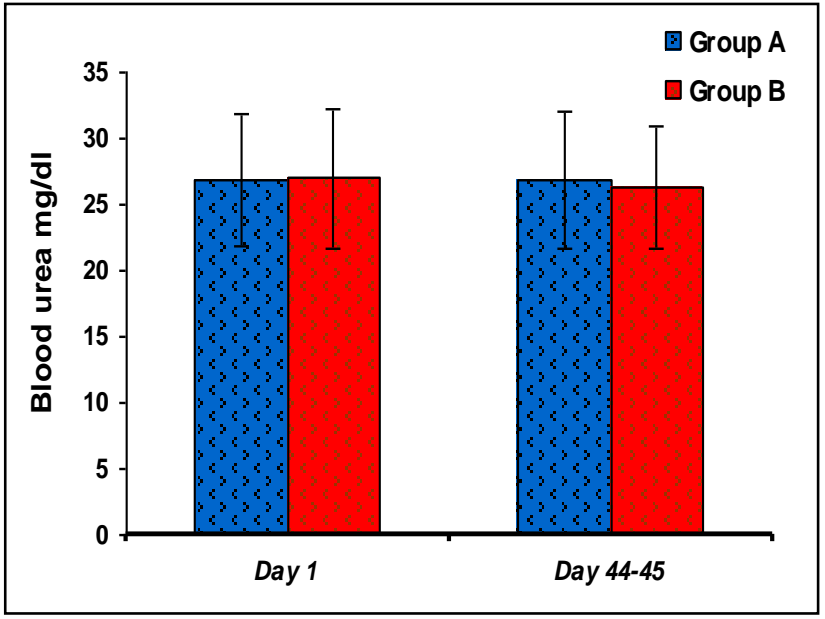

Figure 3: Blood urea in two groups of patients studied on day 1 and day 42-44.

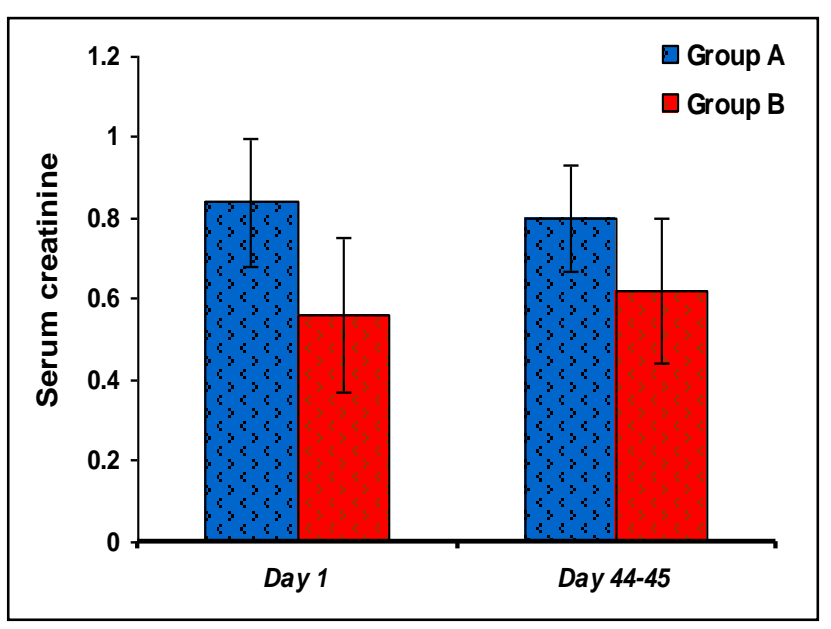

Figure 4: Serum creatinine in two groups of patients studied on day 1 and day 42-44.

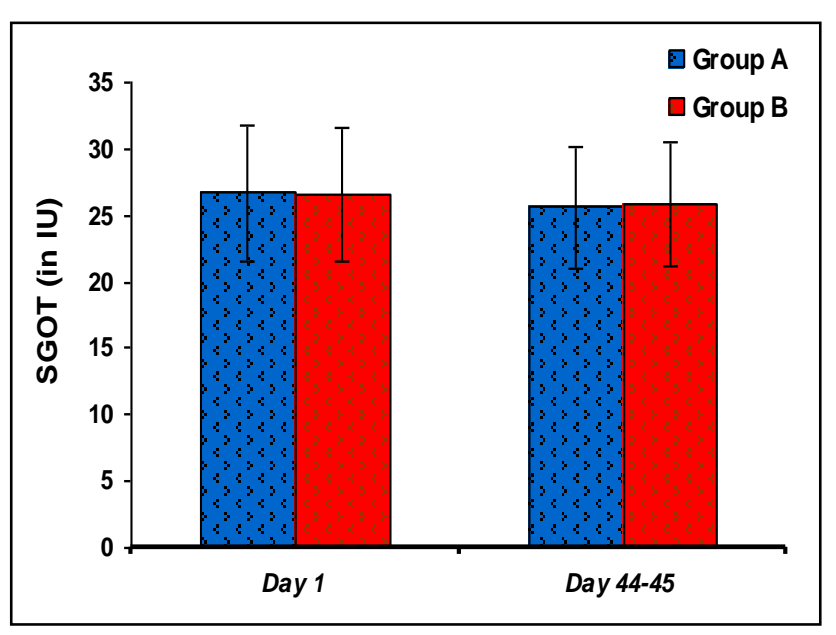

Figure 5: Serum glutamic oxaloacetic transaminase (SGOT) in two groups of patients studied on day 1 and day 42-44.

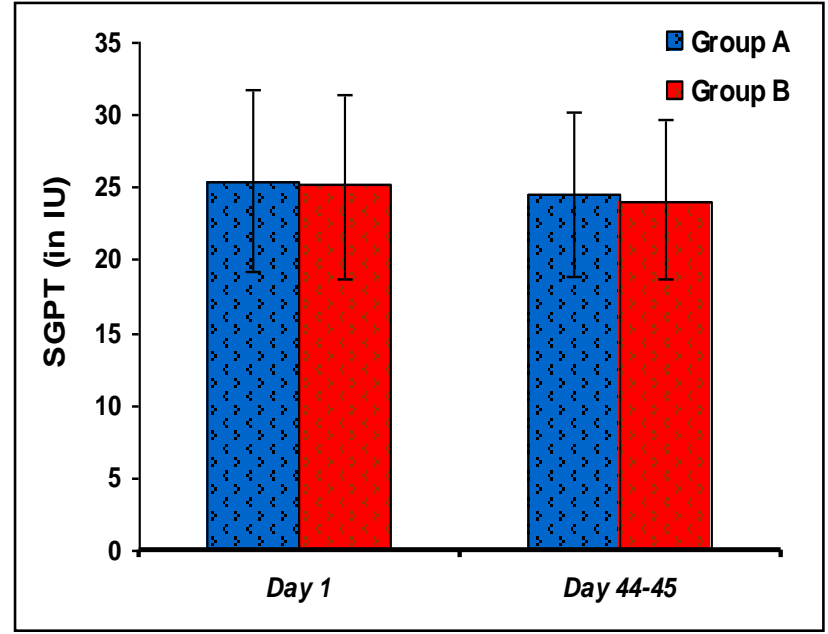

Figure 6: Serum glutamic pyruvic transaminase (SGPT) in two groups of patients studied on day 1 and day 42-44.

Table 3: Side effects reporting on day $14\left(2^{\text {nd }}\right.$ week $)$ in two groups of patients studied (Group A vs. group B).

\begin{tabular}{|llll|}
\hline Side effects & Group A & Group B & p value \\
\hline Nausea & 8 & 4 & 0.218 \\
\hline Vomiting & 6 & 2 & 0.314 \\
\hline Abdominal pain & 14 & 8 & 0.277 \\
\hline Diarrhoea & 13 & 4 & $<\mathbf{0 . 0 5}$ \\
\hline Taste disturbances & 10 & 6 & 0.414 \\
\hline
\end{tabular}

Table 4: Comparison of dyspepsia symptom score on day 1 and day 14 in two groups of patients studied (group A vs. group B).

\begin{tabular}{|c|c|c|c|c|}
\hline \multirow[b]{2}{*}{$\begin{array}{l}\text { Dyspepsia } \\
\text { symptom score }\end{array}$} & \multicolumn{2}{|l|}{ Day 1} & \multicolumn{2}{|c|}{ Day 14 ( $2^{\text {nd }}$ week $)$} \\
\hline & $\begin{array}{l}\text { Group } \\
\text { A }\end{array}$ & $\begin{array}{l}\text { Group } \\
\text { B }\end{array}$ & $\begin{array}{l}\text { Group } \\
\text { A }\end{array}$ & $\begin{array}{l}\text { Group } \\
\text { B }\end{array}$ \\
\hline $\begin{array}{l}\text { (None) } \\
\text { No symptoms }\end{array}$ & 0 & 0 & $\begin{array}{l}30 \\
(60.0 \%)\end{array}$ & $\begin{array}{l}36 \\
(72.0 \%)\end{array}$ \\
\hline $\begin{array}{l}\text { (Mild) } \\
\text { Symptoms can } \\
\text { be easily } \\
\text { ignored }\end{array}$ & 0 & 0 & $\begin{array}{l}19 \\
(38.0 \%)\end{array}$ & $\begin{array}{l}9 \\
(18.0 \%)\end{array}$ \\
\hline $\begin{array}{l}\text { (Moderate) } \\
\text { Awareness of } \\
\text { symptoms but } \\
\text { easily tolerated }\end{array}$ & $\begin{array}{l}39 \\
(78.0 \%)\end{array}$ & $\begin{array}{l}40 \\
(80.0 \%)\end{array}$ & $1(2.0 \%)$ & $4(8.0 \%)$ \\
\hline $\begin{array}{l}\text { (Severe) } \\
\text { Symptoms } \\
\text { sufficient } \\
\text { enough to cause } \\
\text { interference } \\
\text { with normal } \\
\text { activities }\end{array}$ & $\begin{array}{l}11 \\
(22.0 \%)\end{array}$ & $\begin{array}{l}10 \\
(20.0 \%)\end{array}$ & $0(0.0)$ & $1(2.0 \%)$ \\
\hline
\end{tabular}


Table 5: Compliance assessment (day14) in two groups of patients studied (Group A vs. group B) on day 14.

\begin{tabular}{|lllll|}
\hline Compliance & \multicolumn{2}{c}{ Group A } & \multicolumn{2}{c|}{ Group B } \\
assessment & No. & $\%$ & No. & $\%$ \\
\hline $\begin{array}{l}\text { Excellent } \\
\text { (for } 14 \text { days })\end{array}$ & 20 & 40 & 30 & 60 \\
\hline $\begin{array}{l}\text { Good } \\
\text { (10 -14 days) }\end{array}$ & 14 & 28 & 14 & 28 \\
\hline Poor (<10 days) & 16 & 32 & 6 & 12 \\
\hline
\end{tabular}

Dyspepsia symptom score improved in Group B compared to group A $(\mathrm{p}=0.053)$ on day 14 (Table 4). Excellent compliance was seen in $60 \%$ of group B and $40 \%$ of group A patients (Table 5).

\section{DISCUSSION}

Helicobacter pylori infection has been associated with PUD (gastric and duodenal ulcer), gastric carcinoma and gastric MALT lymphoma. So it is necessary to eradicate these bacteria completely in order to treat and prevent above diseases. There is a constant search for an eradication regimen with $>90 \%$ eradication rates, better patient compliance. Along with that cost, simplicity of administration, antibiotic resistance, antibiotic induced side effects, recurrence and relapse of infection need to be taken into consideration while choosing an ideal regimen.

The present study was designed to ascertain if probiotic, prokinetic supplementation to the PPI based regimen (pantoprazole, clarithromycin, amoxicillin) .Group B has better eradication rates, safety and patient compliance compared to conventional USFDA regimen (lansoprazole, clarithromycin, amoxicillin) Group A in the eradication of Helicobacter pylori.

Both amoxicillin and clarithromycin exert a high antiHelicobacter pylori activity and require a twice daily dosage on the basis of their pharmacokinetic properties. Amoxicillin has topical intra-luminal activity at the level of the gastric mucosa, as well as systemic activity. It is actively secreted into the gastric juices from the blood stream. Bioavailability of the clarithromycin is not significantly reduced when the intragastric $\mathrm{pH}$ is low. This helps in achieving good concentrations of the drug in the gastric mucosa. As a single agent amoxicillin and claritromycin achieves eradication rates of $23 \%$ and $54 \%$ respectively. ${ }^{8,9}$ When used in triple therapy these drugs achieve an eradication rate $>80 \%{ }^{10,11}$

Possible role of probiotics in the prophylaxis and treatment of $H$. pylori infection is of increasing interest in the literature. Some in vitro studies showed that probiotics are able to inhibit $H$. pylori by producing different compounds, such as short-chain fatty acids (formic, acetic, propionic, butyric, lactic) and bacteriocins, including nisin $\mathrm{A}$, pediocin $\mathrm{PO}_{2}$, leucocin $\mathrm{K}$, and reuterin (3-hydroxy propionaldehyde). In the last few years, different probiotics have been tested for $H$. pylori eradication. Interestingly, monotherapy with Lactobacillus strains showed a reduction in the $H$. pylori bacterial load in some studies. ${ }^{12,13}$

Addition of prokinetic to H.pylori eradication regimen results in complete symptom improvement in dyspeptic patients leading to improvement in quality of life. Itopride a novel gastro prokinetic agent stimulates gastrointestinal motor activity through dual mode of action antidopaminergic and anti-acetylcholinesterase actions and in addition it has an antiemetic action, accelerates gastric emptying and modulates gastric sensorimotor function. ${ }^{14}$

In our study eradication rate was more with the group B in comparison to the group A (84\% vs. $70 \%)$. The third Maastricht consensus report agreed that effective treatment for H.pylori should achieve an eradication rate over $80 \%$. However, in clinical practise eradication rates are lower than $80 \%$ for many of the standard treatment regimens. $^{2}$

The present study results are similar to a meta-analysis done by Tong JL which showed the eradication rates with or without probiotic supplementation was $(83.6 \%$ and $74.8 \%$ ) respectively. ${ }^{15}$ In a study conducted by Sheu SB showed that Lactobacillus and Bifidobacterium containing yogurt (AB-yogurt) plus quadruple therapy group had a higher $H$. pylori eradication rate than did the quadruple therapy-only group $(85 \%$ compared with $71.1 \%)^{6}$

In contrast to this, study done by Scaccianoce $\mathrm{G}$ on triple therapies plus different probiotics for Helicobacter pylori eradication showed that 7-14 days triple therapy with or without probiotic supplementation failed to achieve acceptable $H$. pylori eradication rates. ${ }^{16}$

Dyspepsia symptom score improved significantly in group B compared to group A after 14 days. Improvement in dyspepsia may be due to addition of prokinetic itopride in group B. In a study conducted by Gerald Holtmann et al concluded that itopride significantly improves symptoms in patients with functional dyspepsia. ${ }^{17}$

38 patients experienced side effects, $23(46 \%)$ in group A and $15(30 \%)$ in group B. Incidence of diarrhoea was statistically less in group $\mathrm{B}$, diarrhoea and abdominal pain were the most common side effect in the group A, whereas abdominal pain was seen more frequently in the group B. All the side effects disappeared spontaneously within 7 days after stoppage of the drug.

In a meta-analysis by Tong JL on the effect of supplementation with probiotics on eradication rates and adverse events during Helicobacter pylori eradication therapy the occurrence of total side effects were $24.7 \%$ and $38.5 \%$ for groups with or without probiotics, 
especially for diarrhoea, the summary Odds Ratio (OR) was $0.44(95 \%$ CI $1 / 40.30-0.66){ }^{15}$

In a study on the effect of oral administration of Lactobacillus $G G$ on antibiotic associated gastrointestinal side-effects during Helicobacter pylori eradication therapy showed that diarrhoea, nausea and taste disturbance were significantly reduced in the Lactobacillus $G G$ supplemented group. An overall assessment of treatment tolerability showed a significant difference in favour of the Lactobacillus $G G$ supplemented group. ${ }^{18}$

Antibiotic-associated gastrointestinal side-effects may represent a serious drawback of triple therapies; even though they are mild in most cases. ${ }^{19}$ The high prevalence of side-effects might cause even motivated and dyspeptic patients to discontinue therapy, with the risk of treatment failure or possible development of antibiotic resistant strains. Gastrointestinal side-effects most often associated with antibiotic treatments may include diarrhoea, nausea, vomiting, bloating and abdominal pain. ${ }^{20}$ These manifestations have been related to quantitative and qualitative changes in the intestinal micro flora due to unabsorbed or secreted antibiotics in the intestinal content, with a resulting reduction in normal saprophytic flora and overgrowth and the persistence of potentially pathogenic antibiotic-resistant indigenous strains. ${ }^{21,22}$

Probiotics are regarded as effective tools for controlling the overgrowth of potentially pathogenic microorganisms and may help to prevent or lower the incidence of antibiotic-associated side-effects.

\section{CONCLUSION}

So, the present study suggests that probiotic and prokinetic supplementation improves eradication rates and decreases antibiotic associated side effects and improves patient compliance. Therefore this novel regimen promises to be better alternative for eradication of Helicobacter pylori as first line therapy compared to conventional USFDA regimen.

\section{ACKNOWLEDGEMENTS}

The authors would like to thank all the staff, department of pharmacology, Bangalore medical college and research institute, Bangalore, for their constant support and guidance and also HOD and staff of department of surgical gastroenterology for their valuable support in making the study successful.

Funding: No funding sources Conflict of interest: None declared

Ethical approval: The study was approved by the Institutional Ethics Committee

\section{REFERENCES}

1. Atherton JC, Blaser MJ. Helicobacter pylori infections. In: Fauci AS, Braunwald E, Kasper DL, Hauser SL, Longo DL, Jameson JL et al. Editors, Harrison's Principles of Internal Medicine. Vol. 1, $17^{\text {th }}$ ed. McGraw hill, New York. 2009:946-9.

2. Chey WD, Wong BCY and the Practice Parameters Committee of the American College of Gastroenterology. American College of Gastroenterology Guideline on the management of Helicobacter pylori infection. Am J Gastroenterol 2007;102:1808-25.

3. Wannmacher L. Review of the evidence for H.pylori treatment regimens. $18^{\text {th }}$ expert committee on the selection and use of essential medicines (Antacids and other antiulcer medicines) - adults and children. 2011;Section 17.1.

4. Malfertheiner P, Megraud F, O'Morain C, Bazzoli F, El-Omar E, Graham D, et al. Current concepts in the management of Helicobacter pylori infection: the Maastricht III. Consensus Report Gut. 2007;56:77281.

5. Kausik SP, Vu C. Helicobacter pylori eradication with lansoprazole, amoxicillin and clarithromycin: testing an ideal regimen in a multicultural south East Asian population and examining factors potentially influencing eradication. Aust $\mathrm{N} Z \mathrm{~J}$ Med. 2000;30(2):231-5.

6. Sheu SB, Cheng $\mathrm{CH}$, Kao WA, Wang ST et al. Pretreatment with Lactobacillus and Bifidobacterium containing yogurt can improve the efficacy of quadruple therapy in eradicating residual Helicobacter pylori infection after failed triple therapy. Am J Clin Nutr. 2006;83:864-9.

7. Ang TL, Fock KM, Teo EK, Chan YH, Ng TM, Chua TS et al. Helicobacter pylori eradication versus prokinetics in the treatment of functional dyspepsia: a randomized, double blind study. J Gastroenterol. 2006;41(7):647-53.

8. Luther J, Higgins PDR, Schoenfeld PS, Moayyedi P, Vakil N, Chey WD. Empiric quadruple vs.triple therapy for primary treatment of Helicobacter pylori Infection: systematic review and meta-analysis of efficacy and tolerability. Am J Gastroenterol. 2010;105:65-73.

9. Goddard AF, Mohamed JJ, Barrett DA, et al. Effect of omeprazole on the distribution of metronidazole, amoxicillin, and clarithromycin in human gastric juice. Gastroenterology. 1996;111:358-67.

10. Hoogerwerf WA, Pasricha PJ. In: Pharmacotherapy of gastric acidity, peptic ulcers and gastroesophageal reflux disease. Bruton LL, Lazo JS, Parker KL. Editors. Goodman and Gillman's The Pharmacological Basis of Therapeutics. $11^{\text {th }}$ ed. McGraw hill, New York. 2001:978-80.

11. Zagari RM, Bianchi-Porro G, Fiocca R, Gasbarrini G, Rodo E, Bazzoli F. Comparison of 1 and 2 weeks of omeprazole, amoxicillin and clarithromycin treatment for helicobacter pylori eradication: the HYPER study. Gut. 2007;56:475-9. 
12. Myllyluoma E, Kajander K, Mikkola H, Kyrönpalo S,Rasmussen M, Kankuri E, et al. Probiotic intervention decreases serum gastrin-17 in Helicobacter pylori infection. Dig Liver Dis. 2007;39:516-23.

13. Cruchet S, Obregon MC, Salazar G, Diaz E, Gotteland M. Effect of the ingestion of a dietary product containing Lactobacillus johnsonii La 1 on Helicobacter pylori colonization in children. Nutrition. 2003;19:716-21.

14. Iwanaga Y, Miyashita N, Saito T, Morikawa K, Itoh $\mathrm{Z}$. Gastroprokinetic effect of a new benzamide derivative itopride and its action mechanisms in conscious dogs. Jpn J Pharmacol. 1996;71:129-37.

15. Tong JL, Ran ZH, Shen J, Zhang CX and Xiao SD, Meta-analysis: the effect of supplementation with probiotics on eradication rates and adverse events during Helicobacter pylori eradication therapy, Aliment Pharmacol Ther. 2007;25,155-68.

16. Scaccianoce G, Zullo A, Hassan C, Gentili F, Cristofari F, Cardinale V, et al. Triple therapies plus different probiotics for helicobacter pylori eradication. Eur Rev Med Pharmacol Sci. 2008;12:251-6.

17. Holtmann G, Talley NJ, Liebregts T, Adam B, Parow C. Placebo-controlled trial of itopride in functional dyspepsia. N Engl J Med. 2006;354:83240.

18. Armuzzi A, Cremonini F, Ojetti V, et al. Effect of Lactobacillus $G G$ supplementation on antibiotic- associated gastrointestinal side effects during Helicobacter pylori eradication therapy: a pilot study. Digestion. 2001;63(1):1-7.

19. Boer WA, Tytgat GNJ. The best therapy for Helicobacter pylori infection: should efficacy or side-effect profile determine our choice? Scand J Gastroenterol. 1995;30:401-7.

20. Marteau P, Rambaud JC. Potential of using lactic acid bacteria for therapy and immunomodulation in man. FEMS Microbiol Rev. 1993;12:207-20.

21. Nord CE, Heimdal A, Kager L. Antimicrobial induced alterations of the human oropharyngeal and intestinal microflora. Scand J Infect Dis suppl. 1986;49:64-72.

22. Adamsson I, Nord CE, Lundquist P, Sjostedt S, Edlund C. Comparative effects of omeprazole, amoxycillin, plus metronidazole versus omeprazole, clarithromycin plus metronidazole on the oral, gastric and intestinal microflora in Helicobacter pylori infected patients. J Antimicrob Chemother. 1999;44:629-40.

Cite this article as: Bharath Kumar VD, Jayanthi CR, Sushma M. A comparative study of probiotic, prokinetic based triple therapy with USFDA regimen in the eradication of H.pylori in a tertiary care hospital. Int J Basic Clin Pharmacol 2016;5:173-9. 